\title{
A REPLY TO PETER LYTH ON WHETHER AN INFINITE TEMPORAL REGRESS OF
}

\section{EVENTS IS POSSIBLE}

\section{Abstract}

Peter Lyth claimed that my argument against an infinite temporal regress of events conflates number as an abstract entity with number as a number of events or things. I show that my argument does not depend on such a conflation.

In his brief reply to my article 'Is an infinite temporal regress of events possible?', ${ }^{1}$ Peter Lyth claimed that my argument conflates number as an abstract entity with number as a number of events or things. ${ }^{2}$ In particular, he asserted (on p.86) that my statements (on p.116) (1) 'the "number" of a set of things is not the sort of entity which in conjunction with the things in the set would have certain causal power that the things would not have had' and

(2) 'it cannot be claimed that "the number (whether finite or infinite) of person-present” in conjunction with "each person subsequently grabbing one present from one position rather than another" would make a difference concerning the presence or absence of causal power with respect to leftovers' conflate number as an abstract entity with number as a number of events or things (Lyth omitted the words in italics in his quotation).

In reply, I do not think that my argument depends on any conflation at all. Perhaps my use of the quotation marks caused the misunderstanding, but I had intended 'number' to be understood in the same sense in both statements, that is, number as an abstract entity with no independent causal power. To clarify: 
In the first sentence, I was arguing that the abstract number of a set of things is not the sort of entity which in conjunction with the things in the set would have certain causal power that the things would not have had.

In the second sentence, I was arguing that it cannot be claimed that the abstract number (whether finite or infinite) of the person-present in conjunction with 'each person subsequently grabbing one present from one position rather than another' would make a difference concerning the presence or absence of causal power with respect to leftovers.

Lyth wanted to claim that 'number as a number of events or things' does have causal power (p.87). However, he did not engage with the explanation I offered in my article with respect to the following question: if any 'number of events or things' has causal power, why does it have causal power?' Lyth insisted that it is the 'totality (involving a number) of each of the things which creates the effect' (p.85), but he failed to engage with my explanation for why the totality has effect (that is, if it has any effect at all). By failing to engage with my explanation, Lyth missed one of the most important points that I was trying to make in the article, namely that the causal powers of a number of entities ultimately depend on whether each of the entities in the set has the relevant causal power.

In what follows, I shall clarify the structure of my explanation and show that my argument does not depend on any conflation concerning number at all.

To begin, consider a number of events or things Y forming a set of Ys.

In my article, I explained that

1. If any set of Ys has causal power with respect to $\mathrm{X}$, this is because each $\mathrm{Y}$ in the set has relevant causal power with respect to $\mathrm{X}$.

To illustrate, let $\mathrm{Y}=10$-pound weights, and let $\mathrm{X}=$ accurate weighing scale.

As I wrote on pp.109-110: 
'Twenty 10-pound weights would make an accurate scale register two hundred pounds under normal circumstances, while ten 10-pound weights would not be sufficient. However, it should be noted that the reason why that is so is because each of the weights has causal power with respect to the scale, in virtue of their mass.'

(It should be noted that Lyth misstated my example of weights. He claimed that I used 'the example of 10-pound weights on a weighing machine, and then 20-pound weights' (p.85). However, the example that I used was different numbers of 10-pound weights).

I had also explained that

2. If each $\mathrm{Y}$ in the set does not have relevant causal power with respect to $\mathrm{X}$, then any set of Ys could not have causal power with respect to X.

As I illustrated on p.110, suppose that a certain entity U has zero mass. In this case, either twenty 'U's or 'ten' 'U's (or indeed any number of 'U's) would not make a difference to the reading on the weighing scale. For $20 \times 0=0,10 \times 0=0$, etc. The result could not be otherwise.

It is evident that the foregoing argument does not conflate number as an abstract entity with number as a number of events or things.

On pages 111-112 and 114-117, I had explained that

3. Each 'person grabbing one present from one position rather than another' has no relevant causal power with respect to the presence of leftover presents (principle P). and

4. If each 'person grabbing one present from one position rather than another' has no relevant causal power with respect to the presence of leftover presents, then any set of 'persons grabbing one present from one position rather than another' could not have causal power with respect to the presence of leftover presents. 
For 3 and 4, I argue in a parallel fashion as 1 and 2, and the argument likewise does not conflate number as an abstract entity with number as a number of events or things.

Now I showed on pp.112-114 that

5. If an infinite number of 'person grabbing one present from one position rather than another' can exist, then a set of 'person grabbing one present from one position rather than another' could have causal power with respect to the presence of leftover presents.

From 4 and 5, it follows that

6. Therefore, an infinite number of 'person grabbing one present from one position rather than another' cannot exist.

I went on to show (on pp.118-120) how this conclusion implies that physical infinities such as an infinite temporal regress of events could not exist.

I also argued that, in order to block this conclusion, the friend of infinity might want to claim that (infinite) number as an abstract entity has causal power, but I argued—and Lyth agreed — that number as an abstract entity do not have independent causal power.

In conclusion, my argument does not depend on a conflation of number as an abstract entity with number as a number of events or things, and hence Lyth has failed to block the conclusion of my argument that physical infinities such as an infinite temporal regress of events cannot exist.

Notes

\footnotetext{
${ }^{1}$ Andrew Loke, 'Is an infinite temporal regress of events possible?’ Think 11(2012):105-122.

${ }^{2}$ Peter Lyth, 'A response to Loke's "Is an infinite temporal regress of events possible?”' Think 13 (2014):85-88.
} 